\title{
Las ciudades latinoamericanas y el coronavirus
}

\author{
Latin American cities and the coronavirus
}

Emilio Pradilla Cobos [I]

Lisett Márquez López [II]

\section{Resumen}

La pandemia del coronavirus llegó a América Latina en 2020, traída por viajeros de estratos sociales medios y altos provenientes de Asia, Europa y Estados Unidos. Se expandió por las grandes ciudades y paso a los sectores populares. La profunda crisis económico-social derivada de la cuarentena impuesta a la población para evitar la propagación del virus, evidenció, nuevamente, las contradicciones, problemas y conflictos que aquejan a los sectores populares en nuestras ciudades capitalistas neoliberales, reconstruidas a la manera del capital inmobiliario financiero trasnacionalizado y las políticas estatales que promueven y facilitan su actuar. Ahora y en la pospandemia, se impone la reivindicación del derecho a la ciudad transformada en una nueva sociedad, tal como propuso Henri Lefebvre hace medio siglo.

Palabras clave: coronavirus; ciudad neoliberal; América Latina; contradicciones urbanas; derecho a la ciudad.

\begin{abstract}
The coronavirus pandemic arrived at Latin America in 2020, brought by middle- and upper-class travelers from Asia, Europe and the United States. It expanded throughout the big cities and passed to the popular sectors. The deep economic-social crisis derived from the quarantine imposed on the population to prevent the spread of the virus has shown, once again, the contradictions, problems and conflicts that afflict the popular sectors in our neoliberal capitalist cities, reconstructed in the manner of transnational financial real estate capital and of state polices that promote and facilitate its actions. Now and in the post-pandemic period, it is necessary to claim the right to the city transformed into a new society, just like Henri Lefebvre proposed half a century ago.
\end{abstract}

Keywords: coronavirus; neoliberal city; Latin America; urban contradictions; right to the city. 
La llegada de la pandemia del coronavirus a distintos países de América Latina en marzo del 2020, teniendo como vehículo a viajeros de ingresos medios y altos provenientes de Asia, Europa o Estados Unidos, para luego expandirse al conjunto de la población, cayó como rayo en cielo descubierto, ante la incredulidad de unos, ${ }^{1}$ la sorpresa de muchos y la preparación apresurada de los menos. Cuando escribimos la versión inicial de este texto, a finales de mayo del 2020, ${ }^{2}$ América era el foco mundial de la pandemia según la Organización Mundial de la salud (OMS), pues Estados Unidos de América (EUA) estaba a la cabeza en la contabilidad de contagiados y muertos, seguido por Brasil, el país más poblado en la región. Hoy, a pesar del desigual avance de la vacunación en curso, México se coloca en el tercer lugar mundial en número de muertos, luego de los dos países antes señalados. Las cifras son contundentes: en América Latina y el Caribe (ALC), el 22 de abril del 2021, los contagiados por Covid 19 llegaban a 27 '645.370, y los muertos a 892.477. Aunque ALC concentra solo al $8,4 \%$ de la población mundial, sumaba ese día el $19,10 \%$ de los contagiados y el $28,72 \%$ de los muertos por Covid 19 en el mundo. Los cinco países latinoamericanos con mayor número de contagiados eran, en orden, Brasil, Argentina, Colombia, México y Perú, mientras que por número de muertos eran Brasil, México, Colombia, Argentina y Perú. Mientras en el mundo la mortalidad ascendía a 40 muertos por 100 mil habitantes, en ALC Ilegaba a 140, Brasil a 182, Perú a 180, México a 168, Panamá a 146, Colombia a 139, Argentina y Chile a 135 (BID, 2021; Cepal, 2021a).
Esta grave crisis sanitaria puso nuevamente en evidencia, dramáticamente, las profundas debilidades y contradicciones sociales de las grandes ciudades latinoamericanas. Estos problemas urbanos, señalados en múltiples trabajos por los investigadores críticos en la década de los setenta del siglo XX en el patrón intervencionista estatal de acumulación de capital (Schteingart (comp.), 1973; Singer, 1975; Pradilla, 1984: cap. 5; entre otros), y en su versión neoliberal (ONU Habitat, 2012; Pradilla, 2014), los cuales no han sido resueltos por las políticas territoriales aplicadas por los sucesivos gobiernos, en la medida que han buscado las alternativas en el mismo modelo de desarrollo capitalista subordinado que los produjo. Ahora, cuando la pandemia hace estragos en los sectores mayoritarios de la población urbana latinoamericana, con distintos grados de vulnerabilidad, las soluciones aplicadas han sido medidas gubernamentales improvisadas que, sin reconocer sus raíces y las determinantes de su crecimiento, en muchos casos ahondarán los problemas; además, hacen Ilamados a una solidaridad que la población brinda sin reparos, pero que no podrá resolver sus impactos en el futuro.

Hay muchos intelectuales y políticos que auguran, como cada vez que hay acontecimientos ${ }^{3}$ no previstos pero significativos que ponen en evidencia viejas contradicciones, que todo va a cambiar después de la pandemia; otros piensan, con argumentos, que todo seguirá igual por el poder del poder, que se beneficia de estas eventualidades; otros pensamos que la ciudad capitalista, inequitativa, autoritaria y 
fragmentadora sólo cambiará si la población mayoritaria exige y conquista el derecho a la ciudad, como lo pensó y propuso Henrí Lefebvre hace cincuenta años, como el derecho de los trabajadores a cambiar y reconstruir la ciudad capitalista en función de sus intereses, necesidades y deseos (Lefebrve, 1968).

Estamos conscientes de que la situación es muy desigual en los países, según su grado de desarrollo capitalista, los patrones de urbanización seguidos, la naturaleza más o menos democrática de sus gobiernos y la fuerza de sus organizaciones sociales, en el pasado y el presente, pero nos vemos forzados a generalizar a toda América Latina, usar sus datos, pues un análisis por país, incluyendo todos los temas previstos Ilevaría mucho tiempo y recursos de los que no disponemos, e implicaría una extensión del texto que sale de las normas de esta revista, para poder llevarlo a cabo coherentemente nos basamos en los rasgos comunes, las regularidades estructurales e históricas que nos permiten hablar de la existencia de América Latina.

\section{La pandemia en la ciudad fragmentada}

Ante la rápida expansión mundial del virus para el que no existía una cura ni una vacuna preventiva, pero que puede ser mortal sobre todo en condiciones de vulnerabilidad, ${ }^{4}$ la campaña antivirus en muchos países del orbe, incluidos los latinoamericanos, se centró en tres consignas: iquédese en casa!, forma voluntaria o forzada represivamente de una "cuarentena"; ino salga a la calle si no tiene que hacerlo!; y iguarde una sana distancia!, tanto en casa como en la calle. La pregunta que debemos responder es: ¿Es posible la "sana distancia" en las hacinadas ciudades y viviendas latinoamericanas?

\section{La "sana distancia" imposible en las metrópolis}

América Latina se acerca a la urbanización total: $81,5 \%$ de su población se aloja en asentamientos reconocidos como urbanos por ONU Habitat (2019b, p. 13); ${ }^{5}$ ocho de las ciudades de la región se sitúan entre las 100 más pobladas del mundo, superando por mucho el millón de habitantes. ${ }^{6}$ Según las proyecciones de la Organización de Naciones Unidas, en 2015 habría en la región 58 ciudades con más de un millón de habitantes y 9 (la mayoría de las incluidas en la información anterior) albergaban a más de cinco millones de habitantes (ONU Habitat, 2012, p. 186). Dos de estas metrópolis, São Paulo y Ciudad de México, superan ya los 20 millones de habitantes. Hablamos pues de enormes concentraciones de población, que son, por ello, muy vulnerables a la transmisión comunitaria del virus, sobre todo en las áreas de mayor afluencia popular: los centros históricos y sus espacios públicos, las zonas de abasto alimentario y de mercancía barata (mercados públicos formales e informales), el transporte colectivo, etcétera, en los que la "sana distancia" se ha mostrado difícil de aplicar, en particular para quienes viven de y en la calle como los vendedores en la vía pública y otros muchos "informales".

Por su parte, las viviendas populares en nuestras ciudades no reúnen las condiciones materiales básicas para cumplir las exigencias 
de la vida en casa durante los largos períodos de cuarentena, ni para guardar la "sana distancia" entre sus miembros. En 2014, según ONU Habitat (2016, p. 203), el 21,1\% de la población urbana total de América Latina y el Caribe, 104.8 millones de personas, solo un millón trescientas mil menos que en 1990, vivían en los llamados "barrios marginales" caracterizados por viviendas autoconstruidas estrechas y hacinadas, muchas de ellas carentes de servicios básicos. Aunque las viviendas autoconstruidas consolidadas llegan a tener áreas mayores que las promovidas por el sector público, es habitual que las compartan con familiares, o renten parte de ellas para obtener ingresos adicionales. Según Cepal, en 2019, el 73,55 de los habitantes pobres vivían hacinados, con más de dos ocupantes por cuarto (Cepal, 2021b, p. 18).

Desde la implantación del patrón neoliberal de acumulación de capital en la década de los ochenta del siglo XX (Guillén, 1997), los gobiernos latinoamericanos transformaron sus instituciones de vivienda en bancos hipotecarios que financian a sus beneficiarios la adquisición de unidades producidas por el capital privado en conjuntos habitacionales de interés social de mínima superficie (35 a $45 \mathrm{~m}^{2}$ ), alejadas de la periferia urbana, en ocasiones sin servicios públicos básicos, ni acceso a satisfactores urbanos como la educación, la salud y la cultura (Pradilla, 2014). Aún los loft y departamentos producidos en estas décadas por el capital inmobiliario-financiero trasnacionalizado para las capas medias en las áreas centrales de las grandes ciudades (60 a $90 \mathrm{~m}^{2}$ ), no son adecuados para la "sana distancia" y la reclusión prolongada necesarios para el control de la pandemia.

\section{La higiene sin agua ni drenaje}

El problema se hace aún más complejo en las viviendas que carecen de agua potable y sistemas de eliminación de excretas (desagües): $10,5 \%$ y $33,7 \%$ de la población urbana respectivamente (Cepal, 2019b, p. 24), lo cual les dificulta en forma extrema responder a la medida sanitaria de "lávate las manos frecuentemente", evacuar el agua contaminada y quedarse en casa, pues para sobrevivir tienen que salir en busca, al menos, de agua potable para preparar alimentos y beber, además de atender a las medidas contra la pandemia.

Recurrir al uso de gel anti-bacterial, como sustituto del agua, y de cubrebocas, productos que no eran de consumo generalizado, que se agotaron rápidamente en los expendios pues no habían existencias para satisfacer los requerimientos de la pandemia, y han sido objeto de la especulación en un sistema capitalista que se rige por la oferta y la demanda en el mercado, afecta seriamente a los sectores populares que han visto sus empleos e ingresos golpeados severamente por la parálisis de la economía. Aunque recurren a la fabricación de ingeniosos sustitutos caseros para protegerse, los sectores populares no tienen ingresos suficientes para atender estos gastos absolutamente extraordinarios. La situación ha sido aún más grave en la obtención de oxígeno necesario para la atención casera de casos agudos de Covid 19. 


\section{Sistema de salud insuficiente, población sin seguridad social}

Es de todos conocido que la atención a la salud en América Latina está segregada y diferenciada entre un sistema de atención privada de alto costo que incluye medicina especializada, fármacos mercantilizados de patente, y una red de hospitales privados, crecientemente monopolizado y trasnacionalizado, con presencia de fondos privados de inversión, que atiende a la población de ingresos medios y altos, o a los protegidos por seguros privados; $y$ un sistema público que incluye a las instituciones de seguridad social para derechohabientes de empresas públicas y privadas, financiado por cuotas salariales cubiertas por los trabajadores o los empleadores, y además, unidades de atención gratuita en hospitales o centros de salud para la cobertura de población abierta, de ingresos muy bajos y que carece de empleo fijo. Estos sistemas de salud están muy diferenciados en calidad y cobertura, tanto como sus usuarios. También se ha formado, sobre todo en el período neoliberal, un subsistema privado de baja calidad para atender sustitutivamente a los sectores populares que no acceden a los otros dos componentes del sistema público habitualmente saturados, integrado por clínicas y sanatorios precarios, médicos poco especializados, farmacias y fármacos alternativos.

El sistema de salud pública es poco desarrollado históricamente en la región y es deficitario, particularmente para los sectores populares mayoritarios que carecen de derecho a la seguridad social, sobre todo desde la década de los ochenta del siglo XX cuando las políticas neoliberales impusieron el "adelgazamiento del Estado", la reducción sistemática del gasto social público, y la privatización parcial o total de sus equipamientos y servicios (Pradilla, 2009, cap. II). Según la Cepal, "El gasto público del gobierno central en el sector (salud), que en 2018 se ubicaba en el 2,2\% del PIB regional está lejos del 6\% del PIB recomendado por la OPS (Organización Panamericana de la Salud) para reducir las inequidades y aumentar la protección financiera en el marco del acceso y la protección universal" (Cepal, 2020a, p. 10).

La OPS señala que cerca del $30 \%$ de la población de la región carece del ingreso a la salud gratuita que ofrecen los gobiernos, lo cual la coloca en la indefensión ante la enfermedad y, con mayor razón ante una pandemia como la del Covid-19. La Cepal afirma que "hay grandes brechas en el acceso a los sistemas de salud. La participación en los planes de seguro de salud para las personas empleadas de 15 años o más era sólo del $57,3 \%$ en 2016 , y entre la población del decil de ingresos más bajos, la cobertura era de sólo el 34,2\%" (Cepal, 2020d, p. 10).

Diversos medios de comunicación han mostrado las imágenes de posibles contagiados peregrinando en medios de transporte público por los hospitales saturados buscando atención médica y siendo rechazados por falta de cupo, personal médico protestando por falta de insumos adecuados para atender a los enfermos y protegerse ellos mismos, historias de empleados de la salud muriendo por esa razón, funerarias y crematorios desbordados por el aumento del número de cadáveres, cuerpos hacinados en morgues improvisadas o arrojados a la calle por sus familias ante la incapacidad estatal para llevar a cabo su disposición final y el riego epidémico de su conservación. 
A pesar del heroísmo de los trabajadores de la salud en el combate al Covid-19, no tenemos certeza sobre el número real de infectados y muertos por esta pandemia debido a la insuficiencia, ineficiencia operativa, mala calidad y carencia de equipo e insumos, y deterioro de la infraestructura, motivada por la baja inversión estatal histórica en la salud, y por la exclusión creciente de sectores pobres de la población derivada de la privatización neoliberal del servicio y la alta proporción de la población en situación de subsistencia en la informalidad.

\section{Sin la calle para obtener la subsistencia}

La paralización de la economía mundial en los países bajo el régimen de capitalismo neoliberal, en los que la fuerza de trabajo es sólo una mercancía más, una condición necesaria del proceso de valorización, que se licencia apenas éste sufre un freno imprevisto, sin que su manutención y la de su familia preocupe al empresario (Pradilla, 1984, p. 547 y ss.), ha traído como impacto inmediato el crecimiento irrefrenable del desempleo abierto. Los países latinoamericanos, que venían de una recesión económica en 2015-2016, y un débil crecimiento en el período 20142019, únicamente del 0,3\% anual promedio (Cepal, 2021a), han sufrido un aumento del desempleo abierto el cual se estima en 31 millones de trabajadores de tiempo completo que tenían empleo y lo han perdido por la parálisis económica (Cepal y OIT, 2020, pp. 7-8), o reducciones del salario cuando se mantiene. En la mayoría de los países de la región no existe salario de desempleo u otro subsidio estatal similar que mitigue el desempleo.

En 1950, en plena industrialización por sustitución de importaciones, Cepal calculaba el subempleo en $46,1 \%$ de la población económicamente activa (PEA), cifra que sólo disminuyó a 38,3\% en 1980 (Cepal, 1988), para volver a crecer con el neoliberalismo. En 2015, el 46,6\% de la PEA de América Latina y el Caribe se ubicaba en la llamada informalidad, variando entre $30,7 \%$ en Costa Rica y $73,6 \%$ en Guatemala (Casabon, 2017), pero según Cepal, esta cifra era antes de la pandemia de 53\% de la PEA (Cepal, 2020a, p. 6), unos 158 millones de trabajadores. Se trata de una característica estructural de la situación de la fuerza laboral en la región, resultado del carácter tardío, trunco, trasnacionalizado, desigual, estructuralmente contradictorio y lento del desarrollo capitalista agrario e industrial, al cual los gobiernos han enfrentado desigualmente en el tiempo y los territorios con el desalojo, la reubicación, la represión, o la tolerancia por su impotencia para resolverla y la expoliación por la burocracia corrupta, sin enfrentarlo con políticas que beneficien e integren a quienes sobreviven en este sector.

Durante más de siete décadas, este ejército de subempleados ha desarrollado su actividad de subsistencia en las calles, plazas y parques, los lugares de concentración de usuarios de servicios públicos, en mítines y plantones, al aire libre y sus inclemencias, sin servicios sanitarios, sin seguridad social ni acceso a programas de vivienda pública o privada, muchas veces con sus hijos pequeños a cuestas, evadiendo la acción punitiva de las policías o la extorsión de la burocracia. Aún en estas condiciones, sirven a la acumulación 
de capital como reserva de fuerza laboral para las hipotéticas expansiones, como mecanismo para mantener bajos los salarios, de los más bajos del mundo, por el exceso histórico-estructural de trabajadores disponible en el mercado laboral, y como vendedores de sus productos en las calles, al alcance de la gente. Parafraseando a Franz Fanon, podríamos decir que son los "condenados de la ciudad latinoamericana". Pero en la cuarentena de la pandemia, ni en estas condiciones lamentables pueden desarrollar su actividad; un $90 \%$ de los "informales" está siendo severamente afectado en su actividad e ingreso de subsistencia (OIT, 2020). Al decretarse el aislamiento de la población en sus casas, los informales no pueden salir a la calle a realizar sus actividades, ni sus compradores o usuarios deambulan en ellas, perdiendo su fuente diaria de sustento familiar, cayendo en la hambruna.

Este panorama se ha agravado por el impacto negativo de la pandemia en los países desarrollados, EUA en particular, sobre el crecimiento del desempleo entre los inmigrantes indocumentados, la reducción de sus ingresos y las remesas a sus países de origen que permiten la subsistencia a sus familias, acentuados por las agresivas políticas racistas y xenófobas de algunos líderes conservadores o neofascistas, con Donald Trump a la cabeza y la expulsión masiva de migrantes de Centroamérica y México. Esta situación se manifiesta también entre los migrantes de un país latino a otro, o con los desplazados forzosos por la violencia interna cuyo número es muy grande en ciudades colombianas, mexicanas y centroamericanas.

Hay otro sector al cual se menciona poco en los estudios nacionales o de organismos multinacionales por ser ilegal: los "sicarios" del crimen organizado (narcotráfico, contrabando de armas y bienes, trata de personas, explotación sexual, secuestro, robo de mercancías y vehículos, etc.) que parece estar añadiendo nuevos giros de actividad como el "crédito a la palabra" para los otros informales y las pequeñas empresas. Poco sabemos lo que está ocurriendo con ellos, aunque en esta masa hay profundas desigualdades económicas entre la carne de cañón de los operarios, y la estructura organizativa, jerarquizada hasta llegar a las cabezas de las organizaciones; imaginamos diferencias significativas entre estos estratos en la pandemia, aunque los negocios ilegales siguen operando, como lo muestran las cifras rojas del delito.

La pérdida del empleo formal y/o de las actividades callejeras para obtener el ingreso afectan a muchas condiciones de vida: la imposibilidad de pagar la vivienda en renta o en amortización y ser desalojados, los servicios de agua potable, electricidad y teléfono domiciliarios, el transporte público, y lo más inmediato, la carencia de recursos para cubrir los gastos alimentarios cotidianos propios y de la familia, en una población urbana cuyos ingresos alcanzan apenas para sobrevivir o que recibe salarios muy bajos, por lo que carecen de ahorro para cubrirlos durante un periodo que ya sobrepasa los trece meses.

\section{La brecha digital y la educación virtual}

En la era de los discursos triunfalistas sobre el poder transformador de las nuevas tecnologías desplegadas en la ciudad informacional (Castells, 1989), desde los grandes empresarios hasta las burocracias estatales han apostado a 
qué en el aislamiento social, el internet y los aparatos electrónicos harían la diferencia con el pasado, permitiéndonos continuar nuestra vida gracias al trabajo en casa, la educación remota, el mercadeo, abasto, distribución y consumo mediante APPs, así como contactos sociales, sin romper el aislamiento. Pero la realidad ha dicho otra cosa. En América Latina, en 2017 el acceso a internet móvil era muy desigual entre países: en Uruguay, Brasil, Chile y Costa Rica llegaba al $80 \%$ de la población, mientras que en Guatemala, Honduras, Haití y Nicaragua llegaba solo al 30\%; en 2019 el 33\% de la población carecía de acceso a internet (Cepal, 2020a). La brecha digital social excluye a los más pobres de las ciudades y a casi todos los campesinos de las ventajas aportadas por estas herramientas tecnológicas.

El trabajo vía remota es un privilegio de los trabajadores formales de grandes empresas, no de micro y pequeñas, ni de obreros industriales o informales. Los intentos realizados por el aparato educativo público, de primaria a posgrado, de operar vía remota mediante clases virtuales por internet o televisión, enfrenta la limitación de acceso a estos medios por razones económicas, que aumentaron con el desempleo y la pérdida de ingresos, así como la inadecuación de las viviendas precarias para soportar la actividad electrónica simultánea de diversos miembros de la familia, adultos y niños. La capacidad instalada de los sistemas de comercio a distancia y de distribución de mercancías, sobre todo de las subsistencias alimentarias, médicas y de servicios, mostró su insuficiencia ante la demanda masiva de las capas medias y altas en la cuarentena; ni los mercados populares ni sus usuarios usan estos sistemas en la región.
Diríamos que la ciudad de los flujos electrónicos se derrumbó ante la demanda extraordinaria de flujos materiales, debida a la parálisis de los flujos de individuos de carne y hueso. Sin embargo, hay grandes ganadores en esta apuesta a que todo siga igual mediante el uso de las tecnologías de la información: los empresarios de la producción y mercantilización de los equipos electrónicos de cómputo y comunicación, de sus programas y aplicaciones diversas, de las redes sociales, entre los que se cuentan los hombres más ricos del planeta, y en cuyo medio se mueve, como pez en el agua, el capital financiero trasnacional.

\section{El hambre y la solidaridad temporal}

El hambre y la desnutrición, sobre todo infantil, han estado presentes en las ciudades latinoamericanas a lo largo de la historia, en especial desde el éxodo masivo de campesinos pobres en la urbanización acelerada de 1940 a 1980, acompañando a la pobreza y la indigencia permanentes. Sin embargo, el coronavirus y las políticas sanitarias para combatirlo las han puesto en evidencia, casi como un fenómeno nuevo, en los medios de comunicación de masas. Si en julio del 2020, en su informe anual, la FAO (Food and Agriculture Organization) de la ONU calculaba que el hambre afectaba a 50,3 millones de personas en América Latina y el Caribe, sin contar aún con los efectos de la pandemia, por el desempleo y la falta de ingresos que ella genera, esta cantidad podría aumentar hasta en 14 millones más en el 2020 (ONU, 2020; La Jornada, 28-V-2020). Las banderas rojas colombianas, las blancas mexicanas, 
los cartones pidiendo comida, los indígenas haciendo trueque de artesanías por despensas, y otros medios de llamar la atención sobre el hambre y la necesidad de alimentos, se han multiplicado en nuestras ciudades.

El imaginario de la pandemia ha generado un movimiento de solidaridad social que está ayudando a una parte de la población a soportar la hambruna, como insuficiente sustituto paliativo de la limitada acción pública. Esta, limitada en condiciones normales para atender el hambre existente en la región, muy debilitada por la doble disminución de los ingresos fiscales, la estructural por las políticas neoliberales aplicadas durante cuatro décadas y la coyuntural por el débil crecimiento previo a la pandemia y la recesión económica causada por ésta y su combate, es hoy totalmente ineficaz e ineficiente. La pregunta que debemos responder es si las políticas públicas poscrisis, si la pandemia es controlada, estarán en condiciones de enfrentar al hambre y otros graves desajustes sociales que ha producido, en el marco de la lógica neoliberal de mercado; si se debe mantener la solidaridad y la filantropía social para mitigarlas en el mediano y largo plazo; o si debemos exigir la reforma del Estado para que enfrente esa tarea.

\section{Volver pronto a la acumulación, imperativo empresarial y estatal}

No había pasado mucho tiempo de la cuarentena forzosa, cuando algunos gobernantes americanos, encabezados por Donald Trump en Estados Unidos, Jair Bolsonaro en Brasil, Andrés Manuel López Obrador en México, y otros, empezaron a presionar a las autoridades sanitarias y a los gobiernos locales para concluirla y abrir nuevamente la operación de las empresas. Dos exigencias polares los movían: la demanda empresarial de reensamblar las cadenas trasnacionales de valor ${ }^{7}$ y reanudar la acumulación de capital, afectadas por la parálisis económica y la cuarentena, encubiertas por la necesidad de recuperar el empleo perdido; y permitir que la mitad de la población latinoamericana que sobrevive en la informalidad regresara a ganarse la vida cotidianamente en las calles.

Hoy, más de un año después del inicio de la pandemia, cuando las cifras de contagiados y muertos están aún en lo alto en diversos países de la región, Brasil sigue a Estados Unidos con el segundo lugar en el mundo por cifras negativas, México ocupa el tercero en número de muertos, y la vacunación avanza desigual y lentamente según los países, estamos asistiendo en algunos de ellos al "retorno a la nueva normalidad", incluyendo todos los niveles educativos, prematuro, espontáneo o decretado, en medio de una información confusa, mensajes contradictorios de los actores económicos y políticos y desencuentros entre los gobernantes nacionales y locales.

Es interesante observar cuales sectores económicos "no básicos" fueron señalados como "esenciales" para iniciar la reapertura. El caso mexicano es paradigmático: el gobierno federal y algunos estatales eligieron para su reapertura el 10 de junio del 2020, cuando los infectados y muertos iban en aumento, a la industria automotriz, otros giros del transporte como la aeronáutica, la minería, algunos ámbitos relacionados de la maquila, la industria cervecera y la construcción. Salvo la construcción y parte 
de la maquila, todos son giros dominados por empresas monopolistas trasnacionales; la maquila tiene encadenamientos con la industria automotriz, aeroespacial y militar estadounidense y sus autoridades han presionado abiertamente a las mexicanas para su reapertura, aduciendo compromisos firmados en el T-MEC. ${ }^{8}$ Las razones de la reapertura prematura parecen evidentes para la industria de la construcción, crecientemente trasnacionalizada y monopolizada por el capital inmobiliariofinanciero, sustituto de la industria perdida en la desindustrialización, para los procesos de producción de valor y plusvalía, motor de la transformación neoliberal de nuestras metrópolis y fuente de empleo sobreexplotado para muchos trabajadores poco calificados y temporales, (Márquez y Pradilla, 2008; Pradilla, 2014; Pradilla, 2018).

Las preguntas para responder son: ¿cumplirán estas empresas con las complejas y costosas exigencias planteadas por las autoridades para la reapertura? ¿y si no las cumplen, tendrán los gobiernos las herramientas, la decisión política y la capacidad operativa para imponerlas? Nos preocupa que este alineamiento de los gobiernos con el capital trasnacional y su necesidad de reanudar la acumulación de capital en su conjunto, conduzca, por la apertura prematura de la economía, a un rebrote de la pandemia, que afecte directamente a las capas de trabajadores asalariados y se propague a los informales que les aportan bienes y servicios, sobre todo alimenticios, a bajo costo y sobreviven mediante esta actividad.

\section{Un virus con impacto desigual sobre las clases sociales}

En América Latina, la expansión del coronavirus se inició teniendo como portadores a los sectores de ingresos medios y altos que se encontraban como turistas, trabajadores de cuello blanco o negociantes en los países asiáticos primero, y en Europa o Estados Unidos después, afectados inicialmente por el virus. México, por su gran frontera con Estados Unidos y los millones de viajes diarios de migrantes, trabajadores y usuarios del comercio y los servicios entre ambos países fue afectado generalizadamente. Por las actividades comerciales, culturales, políticas, educativas, etc., desarrolladas por estas capas altas, por la cantidad de trabajadores a su servicio o la multiplicidad de contactos que realizan cotidianamente, así como por las altas densidades poblacionales de las grandes ciudades latinoamericanas, rápidamente se empezó a esparcir el virus a los sectores de trabajadores de más bajos ingresos.

Si las capas medias y altas de ingresos, pudieron aislarse en sus viviendas, adecuadas para ello, continuar comprando por vía virtual remota y mensajería con sus ingresos y/o ahorros, usar el automóvil individual para transportarse sin riesgo, recibir información y formación por internet, y recurrir a los seguros de gastos médicos y a la medicina privada, incluyendo hospitales de alto costo, reduciendo el impacto fatal del virus, los sectores de bajos ingresos se enfrentaron, y lo siguen haciendo, a las 
condiciones estructurales negativas antes señaladas, aportando la mayor parte de los contagiados y los muertos en las etapas siguientes de la pandemia.

Podemos afirmar que, aunque los virus no reconocen las clases sociales ni pueden seleccionar a las peor localizadas como objetivo, por las condiciones materiales y sociales de vida ampliamente desiguales entre las clases sociales, estructurales en nuestra región, si están afectando mayoritaria y más agudamente a las clases populares de trabajadores y desempleados; estas situaciones se agravarán en el futuro por la pandemia misma. Por ello, no nos extrañamos que los medios de comunicación señalen que los multimillonarios estadounidenses se han hecho más ricos que antes en estos meses de pandemia, y suponemos que lo mismo ocurre en Latinoamérica, la región más inequitativa del planeta, como siempre ha sucedido en las crisis de diferente naturaleza.

\section{Un futuro poco prometedor}

La incertidumbre sobre el futuro está presente. La apresurada prospectiva oscila entre quienes profetizan que la pandemia va a cambiarlo todo, previendo la desaparición del patrón neoliberal de acumulación o aún del capitalismo, aunque no presentan los trazos de la sociedad que los sustituiría, ni las condiciones políticas y sociales presentes para un cambio tan sustancial; hasta quienes, basándose en las evidencias empíricas y la resistencia de este modo de producir a los embates contrarios, incluidas las revoluciones socialistas realmente ocurridas, pero sin tener en cuenta las fuerzas sociales y su posible reacción a los estragos de la pandemia, piensan que el futuro sería igual o peor que el pasado anterior al coronavirus.

No podemos ni queremos imaginar y describir lo que ocurriría si el coronavirus se mantiene tan letal y agresivo como hasta ahora y no se logra una vacunación generalizada en los países pobres y sin acceso suficiente a las vacunas. En este punto, la ciencia médica y la diplomacia tienen la palabra. Pero creemos que hay que poner en juego muy diferentes procesos para prefigurar lo que podría ocurrir en Latinoamérica y sus ciudades.

\section{La caída histórica del crecimiento económico}

Desde 1982, América Latina ha tenido un bajo crecimiento económico de solo el 2,7\% anual promedio del PIB (Cepal, 2020b, p. 20), sustancialmente menor al que obtuvo entre 1950 y 1980 , de $5,6 \%$ anual promedio (Cepal, 1988, p. 11). El pronóstico inicial de la Cepal para ALC en 2020 era de una caída de -5,3\% del PIB (Cepal, 2020b, p. 16), aunque otros organismos como el Instituto de Finanzas Internacionales consideraban que caería $-7,5 \%$ o más (IFI, 2020); un año después, la proyección para 2020 era una caída de -9,1\% del PIB para la región (Cepal, 2021a, p. 98), y más recientemente, la Secretaria Ejecutiva del organismo hablaba de una caída de $-7,1 \%$ ese año y un pronóstico de $4,1 \%$ de crecimiento, en 2021, mostrando las dificultades que presenta su medición (El Universal, 2021). Los factores que más incidirían en esta caída, según Cepal serían: las muy bajas exportaciones de materias primas agrícolas 
y mineras; la caída de sus precios por la baja demanda, particularmente del petróleo; la disminución aguda del comercio internacional; el éxodo de capitales nacionales y extranjeros hacia los países desarrollados; la parálisis de la inversión nacional y extranjera; la contracción del mercado interno; y la reducción de la actividad productiva, incluyendo notoriamente a la construcción.

Hipotetizando, pensamos que la magnitud del empleo formal recuperado después de la pandemia, dependerá del ritmo de la recuperación de la producción capitalista de punta, de la rearticulación de sus cadenas de valor y del intercambio mercantil de sus productos; igualmente, que cómo señala Cepal, de los cientos de miles de micros, pequeñas y medianas empresas, las que más empleo crean en la región, que han carecido de apoyo estatal y tuvieron que cerrar sus puertas, la mayoría no volverá a abrirlas ni a contratar trabajadores. Sus gestores y trabajadores engrosarán las filas crecientes de los que sobrevivan en la informalidad callejera o en los giros negros y en los ilegales de la violencia individual u organizada, formas históricas de subsistencia de los pobres. La reducción de los recursos fiscales por la recesión llevará a situaciones variables de "austeridad" de los gobiernos que incluirán una disminución impredecible del número de empleados públicos los cuales se sumarán a los liberados por el sector privado, que afectará negativamente la prestación de servicios sociales para los sectores populares, en un momento en que la sociedad los requiere más que nunca para paliar sus necesidades vitales.

El desempleo creciente y el aumento de la informalidad agravarán la situación de pobreza del continente. Cepal, habitualmente moderada en sus cálculos por su carácter institucional, estima que la pobreza y la pobreza extrema aumentaran a $34,7 \%$ y $13,5 \%$ de la población total de América Latina (18 países), un aumento de $4,4 \%$ y $2,5 \%$ en relación con 2019 respectivamente, regresando a cifras similares a las de 2008 (Cepal, 2020b, p. 17), en los escenarios medios proyectados (Cepal, 2020c); al iniciar 2021, su proyección es $1 \%$ menor, en los escenarios medios (Cepal, 2021b, p. 14).

\section{"Regreso a la nueva normalidad"}

En México, los gobernantes han usado indiscriminadamente está consigna sin ningún sentido gramatical pues no se podría "regresar" a algo que es "nuevo", que no se conoce, a una "nueva normalidad". Sin embargo, podríamos encontrarle un sentido si pensamos que podemos "regresar" a algún escenario económico-social que sea una nueva edición de un viejo estatus quo.

La Cepal señala:

Es posible que la mejor solución sea una nueva globalización con una gobernanza proclive a la inclusión y la sostenibilidad, pero para participar activamente en esa nueva globalización, América Latina y el Caribe debe integrarse productiva, comercial y socialmente. Para ello, la coordinación de nuestros países en materia macroeconómica y productiva es crucial para negociar las condiciones de la nueva normalidad, particularmente en una dimensión urgente en la actual crisis y en el mediano plazo: la del financiamiento para un nuevo estilo de desarrollo con igualdad y sostenibilidad ambiental (Cepal, 2020b, p. 20, en negrita en el original). 
Sin elucubrar sobre el sentido que la Cepal da a conceptos como "nueva globalidad", "nueva normalidad", "integración", "gobernanza proclive a la inclusión", "sostenibilidad", "nuevo estilo de desarrollo" e "igualdad", que no se explica en el texto, lo que se nota es que se habla de "globalización", uno de los ejes del patrón de acumulación neoliberal, "gobernanza" entendida como la práctica de los estados liberales consistente en gobernar mediante el consenso de los sectores dominantes y la aceptación pasiva de los dominados, y el "financiamiento" otorgado por los organismos multinacionales Fondo Monetario Internacional y Banco Mundial, propuesto en otros puntos del texto. En ninguna parte se propone un cambio de rumbo económico-social hacia otro patrón de acumulación y otro régimen político para superar la crisis sanitaria y económica que está diezmando a las clases populares, lo que nos lleva a regresar a una normalidad neoliberal cuyos "nuevos" ejes serían las ya muy conocidas adjetivaciones del desarrollo que pululan en los documentos recientes de la ONU, sean generales o urbanos como la Nueva Agenda Urbana de 2016.

La hegemonía en la región de gobiernos conservadores - Perú, Ecuador, Colombia, Uruguay, Paraguay - o aún más a la derecha como los de Bolivia (hasta 2021), Brasil o Chile, y la presencia de unos pocos gobiernos de tendencia "progresista" pero que no han propuesto un modelo económico alternativo al imperante en las últimas cuatro décadas, nos explica el sentido del planteamiento de Cepal, y la tendencia irrefrenable a que los proyectos futuros en lo económico, político y territorial sigan la línea de una "nueva normalidad" neoliberal; claro está, si nuestras sociedades así lo aceptan.

\section{La equidad social y el retorno del Estado}

Como ha ocurrido en episodios anteriores de las grandes crisis cíclicas del capitalismo contemporáneo, en esta ocasión el capital también ha vuelto los ojos hacia el Estado, teniendo en cuenta su función institucional de manejo de los bienes públicos de la sociedad, tanto en términos de patrimonio material como monetario-fiscal. Después de la recesión de 1982, en todo el mundo, el Estado desmanteló las propiedades estatales construidas con el trabajo de toda la sociedad, en un proceso acelerado y sin control de privatización, al tiempo que impuso la reducción de los impuestos que el estado le aplicaba al capital y limitó los controles a su actividad que establecía con su regulación, para resarcirse de la caída de sus ganancias (Offe, 1991). En 1995 y sobre todo después de la recesión de 2008, iniciada en el sector inmobiliario-financiero estadounidense (Parnreiter, 2018, pp. 441-484), optó por que el Estado, con la tributación pública, lo rescatara multimillonariamente, a fondo perdido, de los estragos de sus propios excesos especulativos y sus corruptelas. En 2020, cuando enfrentamos esta grave crisis sanitaria y económica, a la que no son ajenos los procesos acelerados y sin regulación eficaz de destrucción de la naturaleza, de desmantelamiento y privatización mercantil del sistema de salud y protección social de los trabajadores, y del empobrecimiento sostenido de los sectores populares en la región, el capital exige que el Estado asuma la responsabilidad de enfrentar la problemática sanitaria y de subsistencia de la mayoría de la población; y también, sin ninguna razón, que lleve a cabo el rescate de sus empresas, a pesar de que durante cuatro 
décadas ha promovido en lo económico, lo social, lo cultural, su "adelgazamiento" forzado, la reducción de los recursos financieros que se apropia mediante los impuestos, la desregulación y el libre juego del mercado.

Sólo el Estado como institución social sería capaz de enfrentar con alguna posibilidad de éxito una emergencia como ésta. Sin embargo, los estados latinoamericanos, bajo su vestimenta democrático-liberal cubren gobiernos de muchos colores. Desde autoritarios militarizados construidos a partir de golpes militares o formalmente parlamentarios legales, conservadores de diversa orientación, o auto definidos como "progresistas" con participación social restringida, pero subordinados en general a las estructuras económicas neoliberales impuestas a nivel mundial. Sólo si la respuesta de la sociedad a las múltiples crisis sumadas en la presente, se conforma como la creación de una nueva mayoría política construida desde abajo, que acceda al poder del Estado con un proyecto de nación alternativo, podría la región iniciar la construcción de una "nueva normalidad" económico-social que evite que los sectores mayoritarios que pagaron lo fundamental de los costos de la crisis, sean forzados a cubrir los de su recuperación en beneficio del capital.

Señalaremos, para la discusión, algunas propuestas políticas para una "nueva normalidad" alternativa y transicional, indispensables a nuestro juicio para impulsar la transformación de las ciudades latinoamericanas actuales:

Sociedades pluriculturales y con equidad e igualdad de género, que reclamen la inserción soberana y autodeterminada en el contexto mundial, y que en el caso latinoamericano impulsen el proceso de integración económica, política y cultural plural en una Comunidad de Naciones de América Latina y el Caribe.

Regímenes políticos de democracia participativa y representativa auténtica, que lleven a cabo Reformas de Estado para rediseñar y fortalecer la institucionalidad, ampliar sus capacidades y cualidades, su autonomía si es necesaria, así como asegurar un funcionamiento adecuado a las necesidades de la Nación y de los sectores mayoritarios de la población, financiadas mediante reformas tributarias progresivas, para que quienes más tienen más contribuyan: grandes patrimonios, rentas del capital financiero, ganancias empresariales de trasnacionales, capitales en el exterior, herencias, daños ambientales, etc.

Estados de derecho que garanticen la justicia expedita, así como la igualdad real de género, raza y clase social ante la ley, y eliminen el tráfico de influencias, la corrupción y la impunidad.

Economías en continuo proceso de integración regional, reguladas socialmente y estructuradas de acuerdo con las necesidades regionales y nacionales, sustentadas en el trabajo comunitario, equitativas y socialmente justas en la distribución de sus resultados, cuyos objetivos sean la satisfacción de las necesidades de los trabajadores, la garantía del trabajo y los ingresos adecuados, la seguridad y protección social para todos.

Estados cuyas instituciones garanticen a todos la infraestructura, los servicios sociales de educación, salud y vivienda, adecuados a la satisfacción de sus necesidades materiales y sociales, en territorios urbanos y rurales armónicamente desarrollados según sus necesidades, capacidades y aspiraciones diferenciadas, en los que se garantice el 
derecho a la ciudad, entendido como el disfrute pleno de un ámbito territorial equitativo, participativo, igualitario, reconstruido con la participación activa de todos.

Reforma Territorial (rural y urbana) que regule socialmente, en función del interés de las mayorías, el uso del suelo y sus restricciones, la acción del capital inmobiliariofinanciero, la recuperación colectiva de las rentas del suelo, la planeación territorial y, sobre todo, las características morfológicas de la vivienda social, sus agrupamientos y ámbitos comunitarios, así como las condiciones de salubridad y protección social.

\section{¿Qué haremos con la ciudad capitalista neoliberal?}

La pandemia ha disminuido notoriamente la frenética actividad previa del capital inmobiliario-financiero trasnacionalizado y su brazo ejecutor el constructor, al tener que disminuir o cancelar el trabajo productivo debido al obligado aislamiento social. La destrucción de la antigua ciudad y su reemplazo por la capitalista neoliberal, han tenido una pausa, cuyo costo lo han pagado sus trabajadores descalificados, ocasionales y mal pagados, sometidos al paro laboral y la ausencia de ingresos. Pero, en México y otros países, la construcción ha sido considerada "actividad esencial" en la pandemia, reabierta lo más pronto posible debido a la presión e influencia político-económica del capital financiero trasnacional, a la gran cantidad de personal que involucra, y por qué es la rama productora de valor, dinámica en su efecto multiplicador sobre otras ramas y en el empleo, que sobrevive en las metrópolis luego de la desindustrialización de las últimas tres décadas (Márquez y Pradilla, 2008).

El ritmo que tome la destrucción-reconstrucción capitalista de la ciudad dependerá de la recuperación de la acumulación de capital en su conjunto, donde se ubica su demanda, que se prevé lenta en los años próximos, lo cual disminuirá, quizás, los conflictos causados por la renovación urbana, pero sin resolverlos, poniendo en primer plano aquellos de índole económica y social puestos en evidencia por la emergencia sanitaria. Aunque no será extraño que nuestros gobernantes redescubran las "virtudes" de la industria de la construcción y sus "efectos multiplicadores" sobre el desarrollo económico, que ya pusieron en juego, sin mucho éxito, en el pasado (ver el caso colombiano en Pradilla, 1974).

Como investigadores urbanos, debemos dejar atrás las modas analíticas y volver a centrar la mirada en los problemas económico-sociales de las ciudades y sus sectores mayoritarios.

Lo que la pandemia ha evidenciado al mostrar la vulnerabilidad en la que se encuentran las clases trabajadoras oprimidas y explotadas, es que la prioridad fundamental de una nueva política urbana para la reconstrucción debe orientarse hacia la satisfacción de las condiciones individuales y colectivas de vida urbana, de reproducción social de los trabajadores (Pradilla, 1984, cap. 2), incluyendo las infraestructuras y servicios públicos básicos de vialidad y transporte público adecuado, agua potable, drenaje y saneamiento, salud y seguridad social, educación y vivienda adecuada a 
las necesidades reales de la población, lo cual significa colocar la máxima urgencia en el hábitat viejo y nuevo de la población trabajadora mayoritaria: dimensión y otras características físicas de la vivienda, sus formas de agrupamiento, sus ámbitos públicos mínimos, su infraestructura y servicios públicos básicos insustituibles, etc. No se trata solamente de prevenir una nueva pandemia, sino de superar la injusticia social histórica que mostró la que aún no concluye.

La primera prioridad en esa prioridad máxima (reiteración voluntaria) debe ser la reconstrucción y construcción de un sistema de salud para los trabajadores y sectores populares que cubra la demanda cotidiana, sea eficiente, eficaz y de calidad, accesible a todos en sus ámbitos territoriales de vida según las normas internacionales; a ello deben asignarse los recursos obtenidos de los programas de reestructuración de la fiscalidad y el gasto público.

El capital inmobiliario seguirá insistiendo en sus proyectos de renovación urbana, donde obtiene lo fundamental de su acumulación de capital, a la que los gobiernos urbanos y los ciudadanos organizados deberían imponer regulaciones socialmente consensuadas que impidan la segregación por clases sociales mediante la separación de estratos de ingreso, la especulación inmobiliaria y el uso privatizado de los bienes comunes y el ámbito público, que en estas áreas deberán estar a cargo de los empresarios constructores y los usuarios permanentes de las áreas privilegiadas.

Afirmamos que para avanzar en un proyecto democrático, incluyente, equitativo y sustentable de ciudad como el que se derivaría, aún, de una lectura progresista de la propuesta de la Cepal, deberíamos cambiar el rumbo de la planeación y las políticas urbanas. La planeación estratégica y las políticas urbanas facilitadoras aplicadas en el neoliberalismo, originadas en la empresa privada, orientadas a apoyar los proyectos realizados por el capital privado o las Asociaciones Público-Privadas (APP), cuya ineficacia ante situaciones de crisis está demostrada, deben ceder el lugar a otras diferentes: articuladas e integradas a un proyecto de ciudad de largo plazo. Orientadas a satisfacer las necesidades de los sectores mayoritarios de la población urbana, elaboradas por consenso por los sectores sociales mayoritarios y sus formas representativas, en organismos autónomos de los gobiernos de turno; en procesos de evaluación y revisión constantes; aprobadas como leyes por los órganos democráticos de representación legislativa; aplicadas sin modificaciones discrecionales por gobiernos democráticos; con vigilancia ciudadana, rendición de cuentas de los ejecutores y judicialización cuando afectan los intereses colectivos ciudadanos; evaluadas periódicamente por las representaciones ciudadanas para la revisión cotidiana de sus efectos territoriales.

Muchos dirán que el proyecto de ciudad, la planeación y las políticas urbanas democráticas que planteamos, son utópicas. Estamos de acuerdo. Recordemos que las grandes transformaciones sociales en la historia han surgido de utopías viables, que tuvieron condiciones de posibilidad objetiva y fuerzas sociales que las impulsaron: las revoluciones burguesas del siglo XVII y XVIII, las independencias de ALC, la revolución mexicana, la Bolchevique en Rusia, la cubana, la liquidación y fragmentación de la URSS, y muchas otras. Su caracterización y el análisis de lo ocurrido después lo conocemos por 
la historia y la crítica. Aún las propuestas empresariales más dañinas para las sociedades como el liberalismo económico, el equilibrio general del mercado, la libertad de elegir, la democracia liberal, la igualdad ante la ley, etc., han sido utopías nunca alcanzadas o permitidas por sus proponentes a pesar de haber controlado el poder durante cientos de años.

\section{El derecho a la ciudad: una utopía viable}

Hace 50 años, en medio del dominio universal del capitalismo con intervención estatal, el crecimiento económico acelerado y el "estado de bienestar" que permitía la expansión (Offe, 1991), Henri Lefebvre formuló su utopía, en un texto conocido pero que es necesario recordar para recuperar su sentido: ${ }^{9}$

Lo urbano obsesiona a aquellos que viven en la carencia, en la pobreza, en la frustración de los posibles que permanecen sólo como posibles. Así, la integración y la participación obsesionan a los que no participan, a los que no están integrados, aquellos que sobreviven entre los fragmentos de la sociedad posible y las ruinas del pasado: excluidos de la ciudad, a las puertas de "lo urbano". (Lefebvre, 1968, p. 111)

Ellos son los trabajadores, la mayoría de la población de nuestras ciudades, colocados en una situación similar a la de hace medio siglo, sin que el desarrollo capitalista registrado les haya dado las condiciones esenciales de la vida urbana, no los ha integrado a sus beneficios, a su cultura, ni permite que participen en su prospección y gestión.
Imposible concebir la reconstitución de la ciudad antigua, sino solamente la construcción de una nueva ciudad, sobre nuevas bases, a otra escala, en otras condiciones, en otra sociedad. Ni regreso al pasado, (hacia la ciudad tradicional), ni fuga hacia adelante, hacia la aglomeración colosal informe, tal es la norma. (Lefebvre, 1968, p. 117)

El planteamiento central es: no se trata de volver al pasado, que es el presente, o de mejorarla, sino de construir una nueva ciudad, lo cual requiere cambiar la sociedad, pues en la actual es imposible construirla ya que todo se opone al cambio transformador. En América Latina, esta necesidad es apremiante dado que la ciudad actual está atravesada por múltiples problemas y conflictos heredados de su persistente situación de sociedades atrasadas, dominadas y expoliadas desde la colonización por las potencias hegemónicas del capitalismo, lo que les otorga especificidades que las hacen aún más precarias y conflictivas para los sectores mayoritarios empobrecidos, los cuales saldrán de la pandemia en peores situaciones de subsistencia (Pradilla, 2014).

Sólo grupos, clases o fracciones de clases sociales capaces de iniciativas revolucionarias pueden tomar a cargo y llevar hasta el cumplimiento pleno las soluciones a los problemas urbanos; la ciudad renovada será la obra de las fuerzas sociales y políticas. Se trata primero de deshacer las estrategias y las ideologías dominantes en la sociedad actual. (Lefebvre, 1968, p. 126)

Al definir el sujeto social de la construcción de la nueva ciudad, Lefebvre abre el abanico, incluyendo a quienes se proponen 
iniciativas revolucionarias de cambio, indicando que los intelectuales tenemos como prioridad deshacer la bruma ideológica que oculta las miserias del actual patrón neoliberal de producción y reproducción de lo urbano, lo cual se ha realizado desde el inicio de esa nueva cruzada del capital. Por otra parte, ahí está el creciente contingente de desheredados de la ciudad neoliberal, que hace mucho tiempo se organizan en movimientos sociales urbanos y reivindican el cambio, fragmentados lamentablemente por la falta de dirección política ante la profunda crisis del pensamiento y las organizaciones de izquierda luego del estrepitoso derrumbe del seudo socialismo burocrático autoritario que realmente existió.

El derecho a la ciudad no puede concebirse como un simple derecho de visita o de retorno a las ciudades tradicionales. No puede formularse sino como derecho a la vida urbana trasformada, renovada. (Lefebvre, 1968, p. 132)

Reitera que el derecho a la ciudad implica la transformación urbana y no un simple acomodo en la vieja ciudad capitalista neoliberal, o el de los sectores oprimidos y explotados a acceder a algunos de sus satisfactores, o sin exclusiones de raza, credo o género, pero a condición de convertirse en demanda solvente para sus mercancías por el acceso a ingresos o a subsidios benevolentes del poder económico o político. Se trata de conquistar el derecho a la vida plena en otras ciudades diferentes a las actuales.

Hay otro tema que debemos debatir a la luz de las enseñanzas aún frescas de la pandemia: ciudad compacta o desurbanización? A lo largo de la historia de la ciudad capitalista industrial se hicieron diversas propuestas de integración del campo y la ciudad, entre otras cosas, para resolver el hacinamiento, deterioro ambiental, falta de sanidad y malas condiciones de la vivienda, imperantes para los sectores mayoritarios de la población urbana: las propuestas de los socialistas utópicos de fines del siglo XVIII e inicios deI XIX, la ciudad jardín de E. Howard a fines del siglo XIX e inicios del XX, la ciudad lineal de A. Soria en 1885 , la ciudad verde de los desurbanistas soviéticos de finales de la década de 1920, Broadacre City de F. L. Wright en 1932, entre otras (Delfante, 2006), de muy diferentes orientaciones políticas e ideológicas.

En los últimos años, el debate se ha inclinado en los organismos multinacionales, incluida la Organización de las Naciones Unidas, hacia la ciudad compacta, partiendo de los evidentes costos y contradicciones generadas por las acciones de un sector del capital inmobiliario en la llamada ciudad difusa periférica y de las "ventajas" de la práctica modernizante y de alta rentabilidad para el sector inmobiliario-financiero mundializado que reconstruye la ciudad central mediante la verticalización y redensificación sin límites. Nosotros mismos tomamos partido por este patrón de urbanización, aunque partiendo de supuestos teóricos y políticos diversos, relacionados con los intereses mayoritarios de la población. Ahora, tenemos que retomar el debate, el cual supera el alcance de este texto, para el que proponemos que se tome el punto de vista de los sectores mayoritarios de la población urbana latinoamericana, y 
las enseñanzas de sufrimiento y pobreza que ha dejado la pandemia aún inacabada del coronavirus. El desafío que enfrentamos en las ciudades latinoamericanas es encontrar las respuestas, combatir las brumas ideológicas, y logar que se apliquen las reformas que transformen a la ciudad en beneficio de sus sectores mayoritarios.

\section{[I] http://orcid.org/0000-0001-9607-8387}

Universidad Autónoma Metropolitana, División de Ciencias y Artes para el Diseño, Departamento de Teoría y Análisis. Unidad Xochimilco. Ciudad de México, México.

epradillacrm@hotmail.com

\section{[II] https://orcid.org/0000-0003-4626-0361}

Universidad autónoma Metropolitana, División de Ciencias y artes para el Diseño, Departamento de Teoria y Análisis. Unidad Xochimilco. Ciudad de México, México.

lismarq@hotmail.com

\section{Notas}

(1) Varios Jefes de Estado en el mundo dudaron al inicio de la magnitud, transmisibilidad y letalidad del Coronavirus, entre quienes destacan en nuestro hemisferio Donald Trump de Estados Unidos, Jair Bolsonaro de Brasil y Andrés Manuel López Obrador de México.

(2) En este texto usaremos para diversas variables las estadísticas oficiales existentes hasta 2019, previas a la pandemia; y actualizaremos al 22 de abril de 2021 la información sobre ésta, que cambia cada día. Usaremos las estadísticas disponibles para la región, con diversos ámbitos nacionales incluidos según el caso.

(3) En el sentido que le da Fernand Braudel (1970), cuando los señala como contenido esencial del tiempo corto en la historia.

(4) Condiciones de vulnerabilidad: formar parte de la "tercera edad"; y además padecer diabetes, sobre peso, hipertensión y otras cardiopatías, VIH, enfermedades pulmonares, tabaquismo y EPOC, etc., por lo general ligadas a la mala alimentación, por lo que se les suele llamar a algunas de ellas "enfermedades de la pobreza"

(5) Al asumir el criterio de "población urbana" como la concentración mayor de 2.500 habitantes, se incluyen a muchas aldeas rurales; este porcentaje sería menor si se toma un criterio cuantitativo mayor, más real. 
(6) Según los datos del último censo oficial, los cuales pueden ser hasta de hace una década; hay múltiples informaciones y proyecciones que los superan notoriamente, pero no son comparables en términos del territorio asumido y la metodología de cálculo.

(7) Las presiones de la industria automotriz, aeronáutica y militar estadounidense para que se reanudaran las labores de la industria maquiladora mexicana que le provee partes y piezas, desatada en mayo de 2020, es un ejemplo paradigmático.

(8) Tratado Comercial México, Estados Unidos, Canadá (T-MEC) que sustituyó al Tratado de Libre Comercio de América del Norte (TLCAN), y entró en vigor el 1ํ de julio de 2020.

(9) Recurrimos a una traducción propia de la edición francesa original, para evitar cualquier incomprensión que surja de los términos de la traducción castellana citada habitualmente.

\section{Referencias}

BID - Banco Interamericano de Desarrollo (2021). Situación actual de la pandemia. Disponible en: https://www.iadb.org/es/coronavirus/current-situation-pandemic . Acceso en: 23 abril 2021.

BRAUDEL, F. (1970). La historia y las ciencias sociales. Madrid, Alianza Editorial

CASABON, C. (2017). La economía informal de América Latina supera por primera vez la de África Subsahariana. Disponible en: https://www.weforum.org/es/agenda/2017/05/la-economiainformal-de-africa-esta-retrocediendo-mas-rapido-que-la-economia-latinoamericana/. Acceso en: 30 mayo 2018.

CASTELLS, M. (1989). The informational city. Oxford, Basil Blackwell.

CEPAL - Comisión Económica para América Latina y el Caribe (1988). La industrialización en América Latina: evolución y perspectivas, en: SEMINARIO LAS INVERSIONES CONJUNTAS EN LA COOPERACIÓN DE LOS PAÍSES EN VÍAS DE DESARROLLO: EL CASO DE LOS PAÍSES DEL CONO SUR Y DEL BRASIL, 13-15 junio. Anales... Bérgamo y Módena, Agenzia per la mondializzazione dell'impresa, pp. 1-56.

(2019a). Panorama social de América Latina 2019. Santiago de Chile, Cepal.

(2019b.). Anuario estadístico de América Latina y el Caribe. Santiago de Chile, Cepal.

(2020a). América Latina y el Caribe ante la pandemia del COVID 19. Informe Especial n. 1. COVID 19, 3 de abril del 2020. Santiago de Chile, ONU-Cepal.

(2020b). Dimensionar los efectos del COVID 19 para pensar en la reactivación. Informe especial n. 2. COVID 19, 21 de abril del 2020. Santiago de Chile, ONU-Cepal.

(2020c). El desafío social en tiempos del COVID 19. Informe especial n. 3. COVID 19, 12 de mayo del 2020. Santiago de Chile, ONU-Cepal.

(2020d). Masiva pérdida de ingresos impacta a 90\% de los trabajadores informales de América Latina y el Caribe. Disponible en: https://www.ilo.org/americas/sala-de-prensa/WCMS_744298/ lang--es/index.htm. Acceso en: 25 mayo 2020. 
CEPAL - Comisión Económica para América Latina y el Caribe (2021a). Estudio económico de América Latina 2020. Santiago de Chile, ONU-Cepal.

(2021b). Panorama social de América Latina 2020. Santiago de Chile, ONU-Cepal.

CEPAL/OIT - Comisión Económica para América Latina y el Caribe/Organización Internacional del Trabajo (2020). Coyuntura laboral en América Latina y el Caribe. El trabajo en tiempos de pandemia: desafíos frente a la pandemia por coronavirus (COVID 19). n. 22, mayo. Santiago de Chile, ONU-Cepal y OIT.

DELFANTE, C. (2006). Gran historia de la ciudad. De Mesopotamia a Estados Unidos. Madrid, Abada.

EL UNIVERSAL (2021). Covid provocó “aguda” crisis económica y política del capitalismo global: Cepal. Ciudad de México, 29 de abril del 2021. Disponible en: Cepal: Covid provocó “aguda" crisis económica y política del capitalismo global (eluniversal.com.mx). Acceso en: 29 abril 2021.

GUILLÉN ROMO, H. (1997). La contrarrevolución neoliberal. México DF, México, Era.

IFI - Instituto de Finanzas Internacionales (2020). América Latina va a contracción extremadamente profunda. IFI. La Jornada. Ciudad de México, 26 de mayo. Disponible en: https://www.jornada.com. mx/ultimas/economia/2020/05/26/america-latina-va-a-201ccontraccion-extremadamenteprofunda201d-iif-8965.html. Acceso en: 26 mayo 2020.

LEFEBVRE, H. (1968). Le droit a la ville. Pasris, Anthropos.

MÁRQUEZ, L.; PRADILLA, E. (2008). Desindustrialización, terciarización y estructura metropolitana: un debate conceptual necesario. Cuadernos del Cendes. Caracas, n. 69, pp. 21-45.

OFFE, C. (1991). Contradicciones en el Estado del bienestar. México DF, Conaculta/Alianza Editorial.

ONU HABITAT (2012). Estudio de las ciudades de América Latina. Río de Janeiro, ONU-Habitat.

(2016). Reporte ciudades del mundo, Estambul, ONU Habitat.

ONU - Organización De Naciones Unidas (2020). La “pandemia del hambre” amenaza a 14 millones en AL por Covid 19: ONU. La jornada. Ciudad de México, 28 de mayo. Disponible en: https://www. jornada.com.mx/ultimas/sociedad/2020/05/28/la-201cpandemia-del-hambre201d-amenaza-a14-millones-en-al-por-covid-19-onu-9072.html Acceso el: 28 mayo 2020.

ONU NOTICIAS - Organización de Naciones Unidas (2020). Cerca de 50 millones sufren hambre en América Latinayel Caribe.13julio. Disponibleen:https://news.un.org/es/story/2020/07/1477361. Acceso en: 22 abril 2021.

OIT - Organización Internacional Del Trabajo (2020). Masiva pérdida de ingresos impacta a $90 \%$ de los trabajadores informales en América Latina y el Caribe. Disponible en: https://www.ilo.org/ americas/sala-de-prensa/WCMS_744298/lang--es/index.htm. Acceso en: 25 mayo 2020.

PARNREITER, C. (2008). Geografía económica: una introducción contemporánea. Ciudad de México, Facultad de Economía, Universidad Nacional Autónoma de México.

PRADILLA, E. (1974). “La política urbana del Estado Colombiano". En: CASTELLS, M. (comp.). Estructura de clases y política urbana en América Latina. Buenos Aires, Ediciones SIAP.

(1984). Contribución a la crítica de la "teoría urbana". Del "espacio" a la "crisis urbana". México DF, Universidad Autónoma Metropolitana, Xochimilco.

(2009). Los territorios del neoliberalismo en América Latina. México DF, Miguel Ángel Porrúa y Universidad Autónoma Metropolitana, Xochimilco. 
PRADILLA, E. (2014). La ciudad capitalista en el patrón neoliberal de acumulación de capital. Cadernos Metrópole. Sao Paulo, v. 16, n. 31, pp. 37-60.

(2018). "Formas productivas, fracciones del capital y reconstrucción urbana en América Latina”. In: CORAGGIO, J. L.; MUÑOZ, R. (comps.), Economía de las ciudades de América Latina hoy, v. I, Enfoques multidisciplinarios. Buenos Aires, Universidad Nacional de General Sarmiento.

SCHTEINGART, M. (comp.) (1973). Urbanización y dependencia en América Latina. Buenos Aires, Ediciones SIAP.

SINGER, P. (1975). Economía política de la urbanización. México DF, Siglo XXI.

Texto recebido em $21 /$ jun/2020

Texto aprovado em 24/jan/2021 